\title{
ANATOMICAL RECONSTRUCTION OF ANTERIOR CRUCIATE LIGAMENT OF THE KNEE: DOUBLE BAND OR SINGLE BAND?
}

Luiz Antonio Zanotelli Zanella' ${ }^{1}$, Adair Bervig Junior' ${ }^{1}$ Augusto Alves Badotti ${ }^{1}$, Alexandre Fróes Michelin², Rodrigo llha Algarve², Cesar Antonio de Quadros Martins ${ }^{2}$

\section{ABSTRACT}

Objective: To evaluate the double-band and single-band techniques for anatomical reconstruction of the anterior cruciate ligament of the knee and demonstrate that the doubleband technique not only provides greater anterior stability but also causes less pain and a better subjective patient response. Methods: We selected 42 patients who underwent anterior cruciate ligament reconstruction, by means of either the single-band anatomical reconstruction technique, using flexor tendon grafts with two tunnels, or the double-band anatomical reconstruction technique, using four tunnels and grafts from the semitendinosus and gracilis tendons. All fixations were performed using interference screws. There was no variation in the sample. Before the operation, the objective and subjective IKDC scores, Lysholm score and length of time with the injury were evaluated. All these variables were reassessed six months later, and the KT-1000 correlation with the contralateral knee was also evaluated. Results: There was no significant difference between the two groups in subjective evaluations, but the single-band group showed better results in relation to range of motion and objective evaluations including KT-1000 (with statistical significance). Conclusion: Our study demonstrated that there was no difference between the two groups in subjective evaluations, but better results were found using the single-band anatomical technique, in relation to objective evaluations.

Keywords - Anterior Cruciate Ligament; Arthroscopy; Sport Medicine

\section{INTRODUCTION}

The anterior cruciate ligament (ACL) is formed by two bands: the anteromedial (AM) and the posterolateral (PL) ${ }^{(1-4)}$. The distal origin of both of these is in the anterior intercondylar area of the tibia, which is located between the medial and lateral tibial spines. The proximal insertion of the ACL is the area below the lateral intercondylar crest, in the lateral femoral condyle ${ }^{(2)}$.

The majority of reconstruction procedures only reestablish one band of the ACL, and thus the long-term results have demonstrated that $11-30 \%$ of the patients treated with this technique present unsatisfactory results ${ }^{(5-7)}$.

In 1995, biomechanical studies demonstrated the importance of reconstruction of the PL band for increasing the rotational stability ${ }^{(1,4,6,7)}$. Mott apud Gabriel et $\mathrm{al}^{(8)}$, in 1983, described the first technique for ACL reconstruction using a double band. This technique then went on being modified over the years, with improvement of the results. Several studies have demonstrated that the double band technique is superior ${ }^{(9-12)}$, but others have not confirmed such findings ${ }^{(13-15)}$.

The doubts regarding whether the technique for anatomical reconstruction of the ACL using a double band is superior are still giving rise to much debate among knee surgeons. The main arguments used by those who still avoid this new technique relate to the

1 - Resident Physician at Passo Fundo Orthopedic Hospital, Passo Fundo, RS, Brazil.

2 - Physician and Preceptor of Medical Residence and the Knee Group, Passo Fundo Orthopedic Hospital, Passo Fundo, RS, Brazil.

Work performed at Passo Fundo Orthopedic Hospital, Passo Fundo, RS, Brazil.

Correspondence: Av. 7 de Setembro 817, Centro, 99010-121 Passo Fundo, RS, Brazil. E-mail: drluizantoniozanella@gmail.com

Work received for publication: September 28, 2010; accepted for publication: June 16, 2011.

The authors declare that there was no conflict of interest in conducting this work 
difficulty in performing the technique, the greater duration of the surgical procedure, the greater cost and the possibility that insufficient graft material will be available.

Our objective in this study was to evaluate the two techniques and prove our hypothesis that the technique for anatomical reconstruction of the ACL using a double band not only provides greater anterior stability, but also causes less pain and a better subjective response among patients.

\section{MATERIALS AND METHODS}

In this double-blind randomized prospective clinical trial, 60 patients (60 knees) underwent surgical reconstruction of the ACL. The inclusion criteria were that the patients should present a unilateral torn ACL, without any meniscal lesion or with a unilateral meniscal lesion covering not more than $25 \%$ of the meniscal surface; they should be between 15 and 40 years of age, without an open growth plate; and they had to have come to the referral hospital between April 2008 and January 2009. The exclusion criteria were ligament lesions on the contralateral knee; ipsilateral ligament lesions in the ankle; previous surgery on either of the knees; and chondral lesions (grade 3 or higher in the Outerbridge classification) ${ }^{(16)}$, and this was verified during this operation.

The patients were divided into two groups of 30 , and this division was done randomly using sealed envelopes. The draw was performed by the surgical support team immediately before the operation. The operations were performed by two knee surgeons, who both had the technical knowledge and experience for carrying out these procedures, and they were together in the surgical theater during all the procedures. Neither the patients nor the postoperative assessment team knew which group the patient had been allocated to. The medication used during the immediate postoperative period was standardized, and only medications for daily use were added to this. The latter were not analgesics or non-steroidal anti-inflammatory drugs (NSAIDs).

\section{Clinical follow-up}

Before the operation, on the day on which the operation was scheduled, an assessment was made at the referral hospital using the Lysholm, subjective IKDC and objective IKDC questionnaires.
On the postoperative return visit $\left(15^{\text {th }}\right.$ day), the patient was released for full weight-bearing. No tests were performed until the $180^{\text {th }}$ day after the operation, when the patients underwent functional tests using KT-1000, objective IKDC, subjective IKDC and Lysholm. At this consultation on the $180^{\text {th }}$ day, the patient was given guidance regarding physical activity and released in this respect. It is important to emphasize that none of the pre or postoperative examiners knew which group the patient belonged to.

\section{Rehabilitation}

The two groups received the same physiotherapy protocol. Passive continuous movement was started on the first day, and the patients were released for partial load-bearing. Full load-bearing was allowed two weeks after the operation. The patients were released for sports activities six months after the operation.

Among the 30 patients who were allocated to the group receiving the technique for anatomical reconstruction of the ACL using a single band, three were excluded from the study because of transoperative findings that were among the exclusion criteria, such as an extensive meniscal lesion (two patients) and cartilaginous lesions (one patient); five patients did not return for a new assessment after 180 days; and one patient returned after 180 days with a rerupture of the ACL graft. However, from anamnesis conducted with this patient, it was learned that he had not complied with the medical guidance and had returned to exhaustive sports activities only 90 days after the operation. Therefore, this patient was excluded from the analysis. In this manner, 21 patients were selected.

Among the 30 patients allocated to the group with ACL reconstruction using the double-band anatomical technique, three were excluded because of transoperative findings: two due to extensive meniscal lesions and one due to cartilaginous lesions. Also during the operation, in the cases of two patients, the graft material was not big enough to perform the technique and these patients were excluded from the study. In addition, one patient returned with a torn graft and excluded. Three patients in this group were also lost from the postoperative follow-up. In this manner, 21 patients were selected.

\section{Operative technique}

The incisions made were identical in the two groups. Graft material from the tendons of the 
semitendinosus and gracilis muscles was harvested by means of an oblique anteromedial incision above the pes anserinus, and for both groups, the dissection was performed using a tendon-stripper (ST8850, Conmed Linvatec). The grafts were then cleaned and measured, seeking the length necessary for reconstruction using two double tendons in a double band or quadruple flexors in a single band. These were prepared using "baseball” sutures, with Vicryl ${ }^{\circledR}$ no. 1.0 absorbable thread (Polyglactin 910, Ethicon Inc), to keep the two bundles together, in the case of using double bands, or the four bands together, in the case of using single bands.

In the case of the double-band reconstruction technique, the tendon of the semitendinosus muscle was used for the anteromedial band and the tendon of the gracilis muscle for the posterolateral band.

Conventional PL and AM portals were made and, after insufflation with serum, a rigorous joint inventory was conducted, to look for abnormalities that might be among the exclusion criteria. When necessary, meniscectomy and/or debridement were performed before starting the ligament reconstruction. The stumps of the ACL were carefully identified and debrided in cases of each of the techniques, thereby minimizing the possibility of error in positioning the tunnels, through direct viewing of the insertion sites.

In the technique of anatomical reconstruction of the ACL using a single band, a guidewire was passed through the tibia using a tutor, at an approximate angle of $55^{\circ}$ to the sagittal plane. The exit point for the wire was at the center of the site of the original insertion (the attachment point).

The femoral tunnel was constructed after placement of a guidewire at the center of the site of the previous insertion of the torn ligament, under direct viewing, taking the reference point of the bifurcated intercondylar crest $^{(3)}$. It is extremely important to emphasize that the guidewire and drill bit were passed in through the medial portal that had previously been used for joint inspection. The femoral tunnel was then constructed using a cannulated drill bit that was chosen to be the same diameter as the graft. A depth of $30 \mathrm{~mm}$ was drilled into the femur. After passing the graft material through, the femoral fixation was performed with the knee at $120^{\circ}$ of flexion, using a non-absorbable interference screw. The tibial fixation was performed with the knee in extension, again using non-absorbable in- terference screws, and these were place distally to the graft. Range-of-motion tests were conducted while the patient was still on the surgical table (Figure 1).

In the technique for anatomical reconstruction of the ACL using a double band, the graft harvesting was done using the same technique as described above. After making the joint inventory, the tibial bed was prepared for construction of the AM and PL tunnels. The AM tibial tunnel was constructed taking the basis of the anteromedial portion of the center of attachment of the original ACL, at an angle of $55^{\circ}$ in the sagittal plane and $10-15^{\circ}$ in the coronal plane, while maintaining the line of the tibial diaphysis as a guide. The PL tibial tunnel was positioned posterolaterally in relation to the original attachment, at an angle of $45^{\circ}$ in relation to the tibial axis in the sagittal plane and $45^{\circ}$ in the coronal plane. The tunnels were drilled using a bit of the same diameter as the graft.

The femoral tunnels were constructed using a medial transportal technique. The guidewire was positioned under direct viewing, taking the reference point of the bifurcated intercondylar crest $^{(3)}$. The AM band was positioned 4 to $5 \mathrm{~mm}$ posteriorly to the center of the crest, and the PL band was positioned 3 to 4 $\mathrm{mm}$ anteroinferiorly to the central position of the crest, with the knee positioned at $90^{\circ}$. At this degree of knee flexion, the PL band was located at $45^{\circ}$ anteroinferiorly in relation to the AM band. The grafts were fixed to the femur using 7 × $25 \mathrm{~mm}$ non-absorbable interference screws, with the knee at $120^{\circ}$ of flexion. After this, with the knee at $45^{\circ}-60^{\circ}$ of flexion, the graft was fixed in the AM tibial tunnel. Then, with the knee flexed at $0-10^{\circ}$, and with posteriorization and external rotation

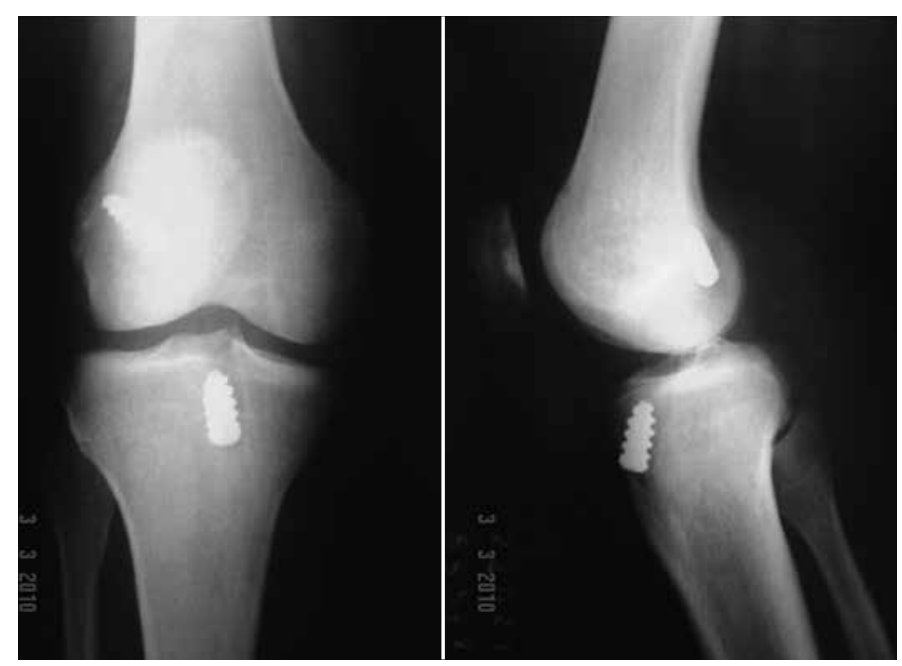

Figure 1 - Radiograph on right knee in anteroposterior and lateral views before the operation, of a patient in the single-band group. 
of the tibial plateau, the graft of the PL band was fixed in its tibial tunnel. All the patients were evaluated regarding their range of motion and joint laxity during the immediate postoperative period (Figure 2).
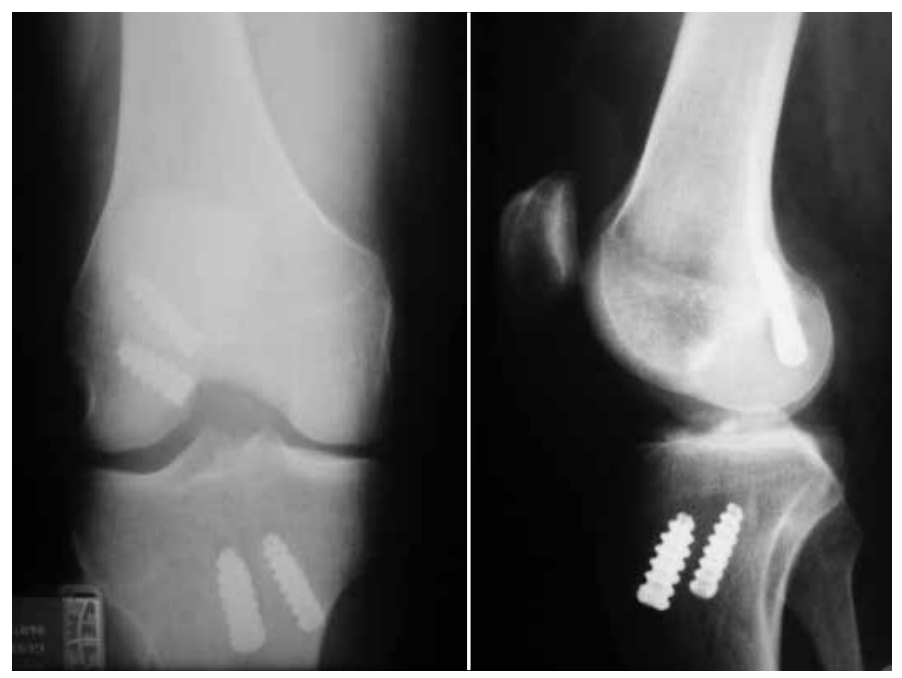

Figure 2 - Radiograph on the right knee in anteroposterior and lateral views after the operation, in the double-band group.

\section{STATISTICAL ANALYSIS}

Student's t test was applied to compare the clinical parameters of the two groups, and the $95 \%$ confidence interval was obtained $(p<0.05)$. Because not all of the grades of the objective IKDC contained patients, it was not possible to perform the chi-square test.

\section{RESULTS}

\section{Analysis on the sample}

The sample consisted of 42 patients in two groups of 21 each, with mean ages of 28.71 years for the single-band group and 29.27 years for the double-band group (Table 1). There was only one female patient in the first group. Based on the data obtained, and from analysis on the preoperative assessments, the Lysholm test, subjective IKDC, length of time with the lesion and pain scale were correlated. For the single-band and double-band groups, respectively, the mean preoperative results were as follows: subjective IKDC score: 48.70 and 52.59; Lysholm score: 57.05 and 59.43; pain scale: 32.05 and 34.05; length of time from injury to surgery: 14.6 and 23.11 months (Tables 2 and 3 ). These did not present any statistically significant difference $(\mathrm{p}>0.05)$, thus showing that there was excellent homogeneity and randomization in the study groups.
Table 1 - Correlation of age with the techniques used.

\begin{tabular}{l|c|c|c|c|c}
\hline \multirow{2}{*}{$\begin{array}{c}\text { Age in } \\
\text { years }\end{array}$} & Technique & $\mathbf{n}$ & Mean & $\begin{array}{c}\text { Standard } \\
\text { deviation }\end{array}$ & p value \\
\cline { 2 - 6 } & $\begin{array}{c}\text { Single } \\
\text { band }\end{array}$ & 21 & 28.71 & 6.286 & 0.736 \\
\cline { 2 - 6 } & $\begin{array}{c}\text { Double } \\
\text { band }\end{array}$ & 21 & 29.43 & 7.318 & \\
\hline
\end{tabular}

Table 2 - Correlation of preoperative variables in the sample.

\begin{tabular}{c|c|c|c|c|c}
\hline & Technique & $\mathbf{n}$ & Mean & $\begin{array}{c}\text { Standard } \\
\text { deviation }\end{array}$ & $\mathbf{p}$ value \\
\hline $\begin{array}{c}\text { subjective } \\
\text { IKDC }\end{array}$ & Single & 21 & 48.7076 & 13.90794 & 0.404 \\
\hline Preoperative & Double & 21 & 52.5981 & 15.92682 & \\
\hline Lisholm & Single & 21 & 57.05 & 15.885 & 0.625 \\
\hline Preoperative & Double & 21 & 59.43 & 15.410 & \\
\hline Pain scale & Single & 21 & 32.05 & 21.704 & 0.767 \\
\hline Preoperative & Double & 21 & 34.05 & 21.773 & \\
\hline
\end{tabular}

Table 3 - Correlation of length of time with the lesion between the two groups. Values in months.

\begin{tabular}{c|c|c|c|c|c}
\hline \multirow{2}{*}{$\begin{array}{c}\text { Length of } \\
\text { time with }\end{array}$} & Technique & $\mathbf{n}$ & Mean & $\begin{array}{c}\text { Standard } \\
\text { deviation }\end{array}$ & p value \\
\cline { 2 - 6 } lesion & Single & 21 & 14.60 & 20.854 & 0.412 \\
\cline { 2 - 6 } & Double & 21 & 23.11 & 42.160 & \\
\hline
\end{tabular}

\section{Postoperative Lysholm and subjective IKDC}

The postoperative subjective IKDC and Lysholm scores were analyzed. These assessments were made by the same examiner, using direct questions, before performing the objective assessments, so that there would not be any assessment bias. However, no statistically significant differences were observed between the two techniques, with $p=0.971$ for the subjective IKDC and $p=0.289$ for Lysholm (Table 4). Thus, the two techniques were shown to be equivalent with regard to these tests.

\section{Objective assessment}

To evaluate ligament laxity, the KT-1000 arthrometer was used (MEDmetric, San Diego, California, USA). This instrument quantifies the anterior and posterior dislocation of the tibia in relation to the femur, in the sagittal plane (Figure 3). By means of applying a tension system $(67 \mathrm{~N}, 89 \mathrm{~N}$ and $134 \mathrm{~N})$, the anterior translation of the tibia in relation to the femur was quantified. This was shown to be an excellent means of assessing passive laxity ${ }^{(17,18)}$. The measurements registered (in $\mathrm{mm}$ ) were seen through a viewer. The number corresponding to the difference between the 
Table 4 - Postoperative correlation of subjective IKDC and Lysholm tests between the groups.

\begin{tabular}{c|c|c|c|c|c}
\hline & Technique & $\mathbf{n}$ & Mean & $\begin{array}{c}\text { Standard } \\
\text { deviation }\end{array}$ & $\mathbf{p ~ v a l u e}$ \\
\hline $\begin{array}{c}\text { subjective } \\
\text { IKDC }\end{array}$ & Single & 21 & 78.05 & 11.385 & 0.971 \\
\hline Preoperative & Double & 21 & 77.89 & 17.717 & \\
\hline Lisholm & Single & 21 & 87.52 & 11.214 & 0.289 \\
\hline Preoperative & Double & 21 & 83.00 & 15.707 & \\
\hline
\end{tabular}

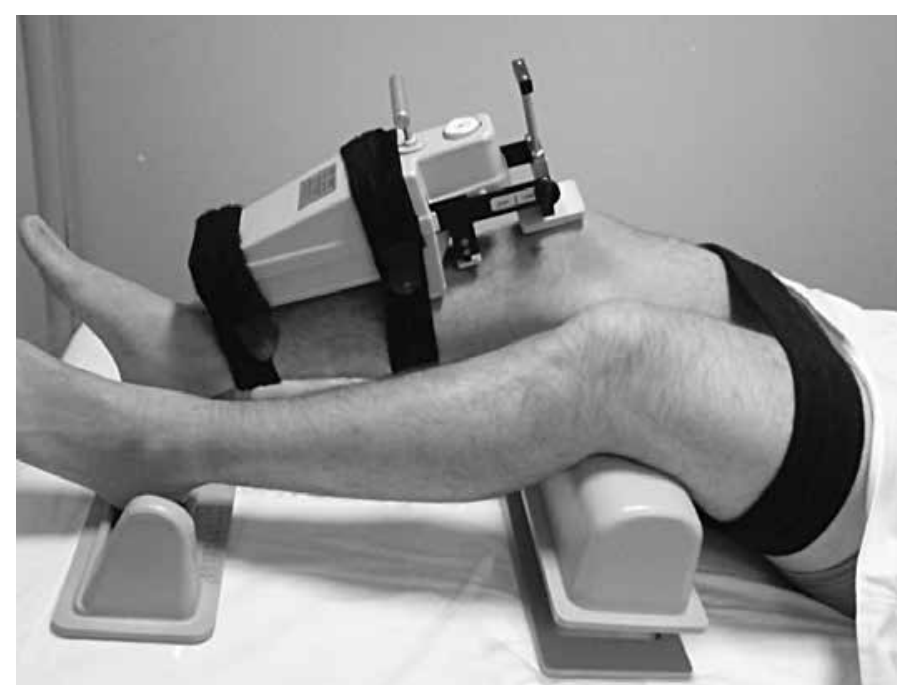

Figure 3 - KT-1000 arthrometer.

limbs was taken to be the amount of the knee ligament laxity, and this was deemed to be normal up to $3 \mathrm{~mm}$.

The test using the KT-1000 was done by the same evaluator on all the patients during their return visit after 180 days of evolution. The operated and contralateral limbs were compared in pairs of repeated tests, thus obtaining three values for each tension in each knee, per test. The difference in tension for each knee was obtained by subtracting the values for the operated knee from the contralateral knee. Thus, positive values represented a laxer knee and negative values represented a firmer knee, in comparison with the contralateral knee (Table 5).

From careful analysis on the results, it was observed that there were statistically significant differences between the techniques in relation to the forces of 67 $\mathrm{N}(0.006)$ and $89 \mathrm{~N}(0.001)$. It was also observed that all the values were lower than $3 \mathrm{~mm}$ (Figure 4).

\section{Assessing the objective IKDC test}

In our study, we observed before the operation that in the single-band group, there were five patients with an extension deficit of $10^{\circ}$. Likewise, in the
Table 5 - Correlation of KT-1000 arthrometer test at tensions of $67 \mathrm{~N}$, $89 \mathrm{~N}$ and $134 \mathrm{~N}$ (maximum) between the two groups.

\begin{tabular}{c|c|c|c|c|c}
\hline & Technique & $\mathbf{n}$ & Mean & $\begin{array}{c}\text { Standard } \\
\text { deviation }\end{array}$ & $\mathbf{p}$ value \\
\hline \multirow{2}{*}{$67 \mathrm{~N}$ test } & Single & 21 & 0.1024 & 0.75901 & 0.006 \\
\cline { 2 - 6 } & Double & 21 & 0.7238 & 0.62782 & \\
\hline \multirow{2}{*}{$89 \mathrm{~N}$ test } & Single & 21 & 0.0810 & 0.83344 & 0.001 \\
\cline { 2 - 6 } & Double & 21 & 0.8476 & 0.59129 & \\
\hline \multirow{2}{*}{$134 \mathrm{~N}$ test } & Single & 21 & 0.3452 & 0.94907 & 0.054 \\
\cline { 2 - 6 } & Double & 21 & 0.8952 & 0.83933 & \\
\hline
\end{tabular}

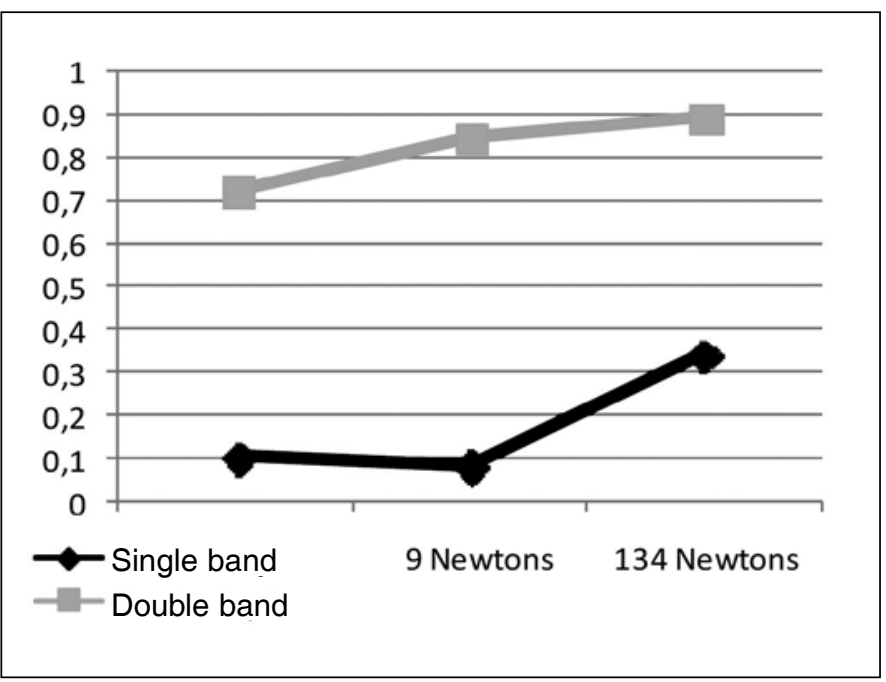

Figure 4 - Difference in mm between KT-1000 values.

double-band group, there were four who had lost $10^{\circ}$ and one who had lost $35^{\circ}$ of extension. None of the patients presented flexion loss.

After the operation, in the single-band group, there was only one patient with an extension loss of $10^{\circ}$ of range of motion. However, in the double-band group, extension loss was presented by four patients: two with losses of $5^{\circ}$ and two with losses of $10^{\circ}$.

From the graph in Figure 5, the single-band group before the operation showed a greater number of patients with " $A$ " results, but not as many patients with " $\mathrm{D}$ ” results. Thus, this represents a possible selection bias in our study.

\section{DISCUSSION}

From reviewing the literature, we found several articles on this topic. Some authors advocate using a double band, but others do not. In theory, a double band presents several advantages, such as making a greater graft-bone area available, thereby favoring greater anchorage of collagen fibers ${ }^{(19-21)}$. Construction of the tunnels can be done independently, thus 


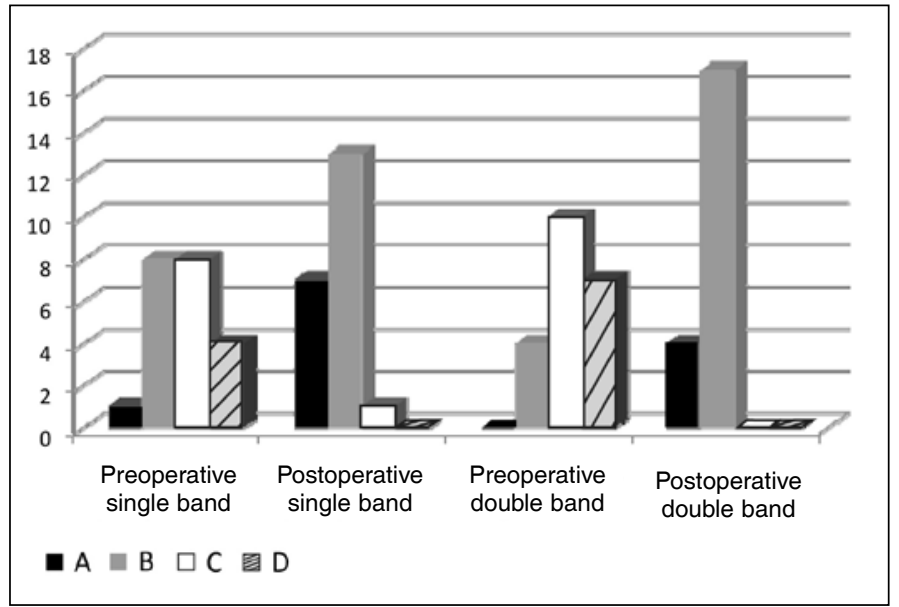

Figure $\mathbf{5}$ - Pre and postoperative values in each group correlated with objective IKDC classes.

ensuring that the correct angle is used for each band, as described by Yasuda et $\mathrm{al}^{(13)}$. Biomechanical studies have demonstrated what individual contribution each band has towards ACL function. Sakane et al ${ }^{(22)}$ demonstrated that the AM band presented constant tension levels during knee flexion, and that the PL band presented greater variability of tension, with greatest levels between 0 and $30^{\circ}$, and thereafter decreasing with gradual flexion of the knee. These data were confirmed by Amis and Zavras ${ }^{(1)}$, who demonstrated tension of $67 \mathrm{~N}$ (in situ) in the PL band in extension and $90 \mathrm{~N}$ in the AM band with the knee flexed at $60^{\circ}$. Another advantage was demonstrated by Gabriel et $\mathrm{al}^{(8)}$, who showed that the PL band contributed especially towards the rotational stability of the knee at flexion of $15^{\circ}$ to $30^{\circ}$. On the other hand, we emphasize that using the technique for double-band reconstruction is a challenge for surgeons, since it requires greater expertise and experience, takes longer to perform and presents patient-dependent factors regarding graft quality, such that the graft needs to be long enough and thick enough to construct the two bands, and regarding bone quality, which has to be good enough to construct the tunnels.

In 2008, in a randomized clinical study on a series of 70 patients allocated into two groups, Siebold et $\mathrm{al}^{(11)}$ demonstrated that the rotational and anterior stability of knees with double-band ACL reconstruction, using an anatomical technique, was greater in KT-1000 and objective IKDC tests than was the stability of ligament reconstructions using the single-band technique. However, when the data were analyzed with regard to the Cincinnati, Lysholm and subjective
IKDC scores, there was no statistically significant variation in the results between the groups.

Similar results had previously been observed by Muneta et $\mathrm{al}^{(12)}$, in a series from 1992 to 1996 , in reconstructions using flexor tendons in a single or double band, in which the measurement parameters were the Lachman test and anterior stability from KT-1000. The results indicated that the results from reconstructions using the double-band technique were superior.

In 2004, Yasuda et al ${ }^{(13)}$ presented a technique for double-band anatomical reconstruction in a study that compared three techniques: ACL reconstruction using a single band; ACL reconstruction using a double band and three tunnels (of which two were femoral); and lastly, ACL reconstruction using a double-band anatomical technique with four tunnels. The results demonstrated that the anatomical technique of double-band reconstruction was statistically superior, when assessed using KT-1000 and pivot-shift. The clinical results of Zhao et $\mathrm{al}^{(14)}$, in 2006 , further confirmed these results with regard to anterior and rotational stability.

However, in 2004, contrary to previous studies, Adachi et $\mathrm{al}^{(15)}$ did not find any differences between the classic techniques of ACL reconstruction using a single or a double band, with tendons from the semitendinosus and gracilis muscles in both cases. Likewise, Hamada et $\mathrm{l}^{(16)}$ did not find any significant difference between the single and double band techniques, regarding anterior instability of the knees.

Also in disagreement with previous studies, in a series of 123 patients that compared the single and double band techniques and analyzed knee laxity, range of motion, extension and flexion strength (determined using Cybex), anterior instability (KT-1000) and Lysholm score, Asagumo et $\mathrm{al}^{(17)}$ (2006) did not find any significant differences except in the range of motion, in which the double band was inferior. Thus, these authors did not corroborate adoption of the double band technique.

In our study, we made observations in a satisfactory sample, albeit with evaluation bias due to the impossibility of objectively measuring the internal rotation of the tibial plateau after the reconstruction. Our results with the double band were not as good as we had expected. We did not observe any significant improvement in any subjective score, but even though we achieved knees that were less rigid, they were firm, as shown by the results from the KT-1000 and 
objective IKDC tests. The reason for this may lie in the fixation angle of the PL band. This structure became fragile and may have been responsible for the loss of extension, which was initially greater in the double band group.

One explanation for these results may be that we were comparing the double band technique with an anatomical single band technique, rather than with the conventional single band technique (transtibial), thereby leading to a result that was not as good as expected. Like Asagumo et al ${ }^{(17)}$, we observed a greater loss of extension in the double band group, which is making us think again about our use of this technique.

\section{CONCLUSION}

In the present study, we did not find any difference between the two groups in the subjective evaluations. However, in the objective evaluations, we observed better results from the single-band technique. Thus, we were unable to prove that anatomical reconstruction using a double-band was superior. However, it should be emphasized that there is a need for studies with longer follow-up in order to make assessments regarding the development of gonarthrosis (a late complication from instability), which might perhaps be avoided with this new technique.

\section{REFERENCES}

1. Amis AA, Zavras TD. Isometricity and graft placement during anterior cruciate ligament reconstruction. Knee. 1995;2(1):5-17.

2. Harner CD, Baek GH, Vogrin TM, Carlin GJ, Kashiwaguchi S, Woo SL. Quantitative analysis of human cruciate ligament insertions. Arthroscopy. 1999;15(7):741-9.

3. Martins CAQ, Kropf EJ, Shen W, van Eck CF, Fu FH. The concept of anatomic anterior cruciate ligament reconstruction. Oper Tech Sports Med. 2008;16:104-115.

4. Carneiro M, Navarro RD, Nakama GY, Barreto JM, Queiróz AAB, Luzo MVM. Reconstrução do ligamento cruzado anterior com duplo feixe utilizando os tendões dos músculos semitendíneo e grácil: fixação com dois parafusos de interferência. Rev Bras Ortop. 2009;44(5):441-5.

5. Bach BR Jr, Tradonsky S, Bojchuk J, Levy ME, Bush-Joseph CA, Khan NH Arthroscopically assisted anterior cruciate ligament reconstruction using patellar tendon autograft. Five- to nine-year follow-up evaluation. Am J Sports Med. 1998;26(1):20-9.

6. Aglietti P, Buzzi R, D'Andria S, Zaccherotti G. Long-term study of anterior cruciate ligament reconstruction for chronic instability using the central onethird patellar tendon and a lateral extraarticular tenodesis. Am J Sports Med. 1992;20(1):38-45.

7. Lohmander LS, Ostenberg A, Englund M, Roos H. High prevalence of knee osteoarthritis, pain, and functional limitations in female soccer players twelve years after anterior cruciate ligament injury. Arthritis Rheum. 2004;50(10):3145-52.

8. Gabriel MT, Wong EK, Woo SL, Yagi M, Debski RE. Distribution of in situ forces in the anterior cruciate ligament in response to rotatory loads. J Orthop Res. 2004;22(1):85-9.

9. Yagi M, Wong EK, Kanamori A, Debski RE, Fu FH, Woo SL. Biomechanical analysis of an anatomic anterior cruciate ligament reconstruction. Am J Sports Med. 2002;30(5):660-6.

10. Mott HW. Semitendinosus anatomic reconstruction for cruciate ligamentinsufficiency. Clin Orthop Relat Res. 1983;(172):90-2.

11. Siebold R, Dehler C, Ellert T. Prospective randomized comparison of doublebundle versus single-bundle anterior cruciate ligament reconstruction. Arthroscopy. 2008;24(2):137-45.

12. Muneta T, Koga H, Morito T, Yagishita K, Sekiya I. A retrospective study of the midterm outcome of two-bundle anterior cruciate ligament reconstruction using quadrupled semitendinosus tendon in comparison with one-bundle reconstruction. Arthroscopy. 2006;22(3):252-8.

13. Yasuda K, Kondo E, Ichiyama H, Kitamura N, Tanabe Y, Tohyama H, et al. Anatomic reconstruction of the anteromedial and posterolateral bundles of the anterior cruciate ligament using hamstring tendon grafts. Arthroscopy. 2004;20(10):1015-25.

14. Zhao J, Peng X, He Y, Wang J. Two-bundle anterior cruciate ligament reconstruction with eight-stranded hamstring tendons: four-tunnel technique. Knee. 2006;13(1):36-41.

15. Adachi N, Ochi M, Uchio Y, Iwasa J, Kuriwaka M, Ito Y. Reconstruction of the anterior cruciate ligament. Single- versus double-bundle multistranded hamstring tendons. J Bone Joint Surg Br. 2004;86(4):515-20.

16. Hamada M, Shino K, Horibe S, Mitsuoka T, Miyama T, Shiozaki Y, et al. Singleversus bi-socket anterior cruciate ligament reconstruction using autogenous multiple-stranded hamstring tendons with endoButton femoral fixation: A prospective study. Arthroscopy. 2001;17(8):801-7.

17. Asagumo H, Kimura M, Kobayashi Y, Taki M, Takagishi K. Anatomic reconstruction of the anterior cruciate ligament using double-bundle hamstring tendons: surgical techniques, clinical outcomes, and complications. Arthroscopy. 2007;23(6):602-9.

18. Outerbridge RE. The etiology of chondromalacia patellae. J Bone Joint Surg Br. 1961;43:752-7.

19. Tomita F, Yasuda K, Mikami S, Sakai T, Yamazaki S, Tohyama H. Comparisons of intraosseous graft healing between the doubled flexor tendon graft and the bone-patellar tendon-bone graft in anterior cruciate ligament reconstruction. Arthroscopy. 2001;17(5):461-76.

20. Cho S, Muneta T, Ito S, Yagishita K, Ichinose S. Electron microscopic evaluation of two-bundle anatomically reconstructed anterior cruciate ligament graft. J Orthop Sci. 2004;9(3):296-301.

21. Gali JC, Mod MSB, Mimura HM, Kushiyama W. Reconstrução anatômica do ligamento cruzado anterior com dupla banda: estudo prospectivo com seguimento de dois anos. Rev Bras Ortop 2011;46(1):31-6.

22. Sakane M, Fox RJ, Woo SL, Livesay GA, Li G, Fu FH. In situ forces in the anterior cruciate ligament and its bundles in response to anterior tibial loads. J Orthop Res. 1997;15(2):285-93. 